\title{
AN UNUSUAL SLIP OF LATISSIMUS DORSI MUSCLE: A CASE REPORT
}

Swagatika Pradhan1, Dibya Prabha Bara², Chinmayi Mohapatra3 ${ }^{3}$, Rajashree Biswal4, Charulata Sarangi ${ }^{5}$

\section{HOW TO CITE THIS ARTICLE:}

Swagatika Pradhan, Dibya Prabha Bara, Chinmayi Mohapatra, Rajashree Biswal, Charulata Sarangi. "An Unusual Slip of Latissimus Dorsi Muscle: A Case Report". Journal of Evolution of Medical and Dental Sciences 2015; Vol. 4, Issue 20, March 09; Page: 3562-3565, DOI: 10.14260/jemds/2015/514

ABSTRACT: During routine dissection of axillary region of an Indian male adult cadaver we found an unusual slip of latissimus dorsi muscle that located in axilla on both side. This muscular slip was originated from latissimus dorsi muscle fibres, coursing superiorly and anteriorly in oblique fashion into axilla and attached to the pectoralis major muscle fibres. The length of this unusual slip was measured to be $7.4 \mathrm{~cm}$ and width was $1.3 \mathrm{~cm}$. The neurovascular bundle of axillary region were observed beneath this supplementary muscle bundle's arch. Tensions of the axillary region during passive abduction or external rotation of shoulder may be related with the signs and symptoms of neurovascular compression within such anomalies.

KEYWORDS: latissimus dorsi, complete arch, neurovascular compression.

INTRODUCTION: Alexander Ramsay in 1795 for the first time described an oblong muscular slip in axilla stretched from pectoral muscle to latissimus dorsi and teres major muscle. Later this muscular anomaly was confirmed by Langer in 1846. So this variant muscle band is famously called as Langer's axillary arch. Other commonly used nomenclature includes axillopectoral muscle, arcus axillaris, pectodorsal muscle, achselbogen or musculus dorsoepitrochearis. Embryologically this arch is thought to be remnant of panniculus carnosus of lower animals. ${ }^{1}$ This variation is identified in upto $7 \%-13 \%$ of population in cadaveric studies. ${ }^{2}$ Clinically the incidence is $0.25 \%$ to $4 \%$ of total axillary explorations as reported in literatures. Many variants of this muscular arch have been observed regarding its origin, course, size and insertion. But the most commonly described form of this muscle extends from latissimus dorsi to pectoralis major.

CASE REPORT: An unusual muscular slip was encountered during dissection of axillary region of an adult male cadaver by undergraduate MBBS students in SCB Medical college Cuttack. This slip of muscle fibre after taking origin from anterior border of latissimus dorsi, coursed upward superficial to axillary vein and brachial plexus branches inserted into the undersurface of pectoralis major muscle[Figure 1] The length of the band was measured to be $7.4 \mathrm{~cm}$ and width $1.3 \mathrm{~cm}$. The nerve supply of the aforesaid muscle was found to be coming from thoracodorsal nerve. The axillary vein proximal to muscular arch was dilated. No other anatomical abnormalities were found in above cadaver.

DISCUSSION: Accessory muscles in axilla is classified as complete or incomplete. ${ }^{3}$ Complete type span from latissimus dorsi to pectoralis major at its insertion site whereas incomplete type extends from latissimus dorsi and insert not into pectoralis major but on the axillary fascia or into bicep brachi or to the coracobrachialis or to the coracoid process. Our case is a complete type of axillary 


\section{CASE REPORT}

arch. Bertone et al dissected 78 axilla and found 9 cases of axillary arch out of which 6 were complete and 3 were of incomplete type. ${ }^{4}$

Another classification proposed by Uzmensel et $\mathrm{al}^{5}$ according to the various shapes of muscle. In type I, a distinct muscular band having tendinous origin extends from lateral border of latissimus dorsi horizontally and then reaches its insertion by curving anteriorly and superiorly. In type II, a group of fibres lie upward at the lateral side of latissimus dorsi and reach the axilla running superiorly and anteriorly. In type III, a group of fibres from lateral border of latissimus dorsi spreads like a fan and joins the tendinous arch. Our finding is in concordant with type II.

Based on the innervation of this muscular slip, the embryological origin can be established. ${ }^{6}$ If innervated by pectoral nerves, it probably derived from pectoralis major. But in our case the muscle arch was supplied by thoracodorsal nerve, so it can be concluded definitely that it was derived from latissimus dorsi muscle.

Population wise prevalence of this type of variation shows that in Japanese, the prevalence is 9.1\% in 176 cadavers, in Turkish population it is $1.9 \%$ in 26 cadavers. In Bulgarian population 3.6\% and in Spanish population it is reported as 3\% from a study of 50 cadavers. ${ }^{7,8,9,10} \mathrm{~A}$ possible genetic basis has been pointed out by Aziz who found it bilaterally in a patient of trisomy 13.11 Incidence is more common in females than males. It has been shown that presence of axillary arch significantly increases the strength, endurance and motor control of the shoulder along with an increase of paraesthetics in women but not in men. A possible shoulder stabilization and an improved proprioception were also found both in men and most of the women with axillary arch.12

There are many neural, vascular and muscular variations encountered in axilla which are clinically very important due to increasing number of surgical exploration done in here for breast carcinoma, reconstructive procedure and axillary by-pass surgeries. The presence of supernumerary muscle at axillary fossa can make the access to the fossa and their content difficult. Axillary arch muscle has been implicated in the costo-clavicular compression, axillary vein entrapment and median nerve entrapment. ${ }^{13}$ The existence of such arch should be considered in the patients with signs and symptoms consistent with upper extremity neurovascular compression similar to thoracic outlet syndrome. A physical examination may not necessarily reveal all the variants of axillary arch muscle; so magnetic resonance imaging must be needed for accurate diagnosis. ${ }^{14}$

To conclude, reporting this type of muscular variation in axilla is clinically important to plastic surgeons, physiotherapists, oncologists as well as to the radiologists to derive differential diagnosis of shoulder instability and thoracic outlet syndrome.

\section{REFERENCES:}

1. Besana-Ciani I, Grenall MJ. Langer's axillary arch: Anatomy, embryological features and surgical implications. Surgeon. 2005; 3(5): 325-27.

2. Kasai T, Chiba S. True nature of the muscular arch of the axilla and its nerve supply. Kaibogaku Zasshi. 1977; 52: 309-336.

3. Testut L. Les Anomalies Musculaires chez I Homme Expliquees par I Anatomic Comparee et leur Importance en Anthropologie. Paris: Masson; 1884.

4. Bertone VH, Ottone NE, Tartaro ML, Quiros GD, Gonzalez DD, Bonardi PL et al. The morphology and clinical importance of the axillary arch. Folia Morphol 2008; 67(4): 261-266. 


\section{CASE REPORT}

5. Uzmansel D, Kurto AYlu Z, Kara A, OztArk NC. Frequency, anatomical properties and innervation of axillary arch and its relation to brachial plexus in human foetuses. Surg Radiol Anat. 2010; 32: 859-863.

6. Hollinshead WH. Anatomy for surgeons. Volume 3. 3rd ed. Philadelphia; Harper \& Row 1958: 284-300.

7. Kasai T, Chiba S. True nature of muscle of arch of axilla an its nerve supply, 1977, 52(5): 309336.

8. Turgut HB, Peker T, Gulekon N, Anil A, Karakose M. Axillopectoral muscle (Langer's muscle). Clin Anat. 2005; 18: 220-3.

9. Georgiev GP, Jelev L, Surchev L. Axillary arch in Bulgarian population: clinical significance of the arches. Clin Anat. 2007; 20: 286-291.

10. Miguel M, Llusa M, Ortiz JC, Porta N, Lorente M. The axillopectoral muscle (of Langer): Report of three cases. Surg Radiol Anat. 2001; 23(5): 341-3.

11. Aziz MA. Anatomical defects in a case of trisomy 13 with a D/D translocation. Teratology. 1980; 22: 217-27.

12. Clarys JP, Provyn S, Cattrysse E, Snoeck TH, Van Roy P. The role of the axillary arch (of Langer) in the management and the kinesiology of the overhead shoulder mobility, J Sports Med Phys Fitness, 2008, 48(4): 455-465.

13. Loukas M, Noordeh N, Tubbs RS, Jordan R, Variation of the axillary arch muscle with multiple insertions, Singapore Med J, 2009, 50(2): e88-e90.

14. Suzuma T, Sakurai T, Yoshimura G, Umemura T, Shimizu Y, Yang QF et al. Magnetic resonance axillography for preoperative diagnosis of the axillopectoral muscle (Langer'axillary arch): a case report. Breast Cancer. 2003; 10(3): 281-3.

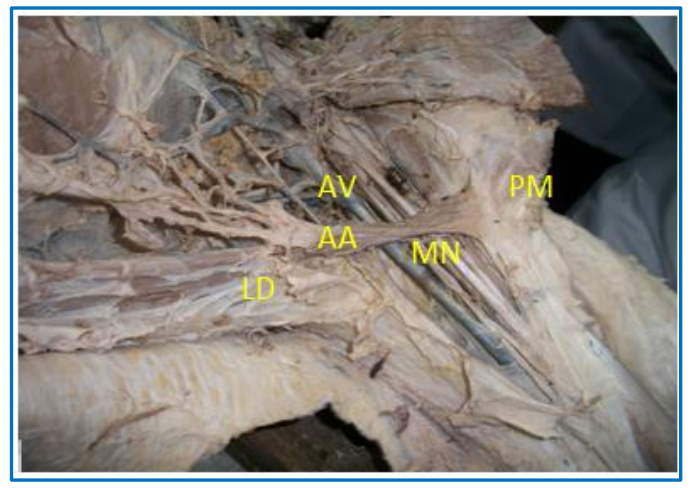

Figure 1: left side axilla showing axillary

\section{ABBREVIATIONS}

AA: Axillary arch.

AV: Axillary vein.

LD: Latissimus dorsi.

MN: Median nerve.

PM: Pectoralis major. 


\section{CASE REPORT}

\section{AUTHORS: \\ 1. Swagatika Pradhan \\ 2. Dibya Prabha Bara \\ 3. Chinmayi Mohapatra \\ 4. Rajashree Biswal \\ 5. Charulata Sarangi}

\section{PARTICULARS OF CONTRIBUTORS:}

1. Senior Resident, Department of Anatomy, S. C. B Medical College Cuttack.

2. Senior Resident, Department of Anatomy, S. C. B Medical College Cuttack.

3. Professor, Department of Anatomy, S. C. B Medical College Cuttack.

\section{FINANCIAL OR OTHER}

COMPETING INTERESTS: None
4. Associate Professor, Department of Anatomy, S. C. B Medical College Cuttack.

5. Associate Professor, Department of Anatomy, S. C. B Medical College Cuttack.

\section{NAME ADDRESS EMAIL ID OF THE}

\section{CORRESPONDING AUTHOR:}

Dr. Swagatika Pradhan,

Senior Resident,

Department of Anatomy,

S. C. B Medical College,

Cuttack-753007, Odisha.

E-mail: swagatika.sagu@gmail.com

Date of Submission: 14/02/2015.

Date of Peer Review: 15/02/2015.

Date of Acceptance: 26/02/2015.

Date of Publishing: 09/03/2015. 